International Journal of Engineering \& Technology, 7 (3.17) (2018) 141-144
International Journal of Engineering \& Technology
SPC
Website: www.sciencepubco.com/index.php/IJET
Research paper

\title{
Wall Heat Transfer Analysis of Internal Combustion Engine with Free Piston Linear Motion
}

\author{
Mior A. Said*, L.K. Mun and A. R. A. Aziz \\ Mechanical Eng. Dept., Center of Automotive Research and Electrical Mobility \\ Universiti Teknologi PETRONAS, 32610 Bandar Seri Iskandar, Perak, Malaysia \\ *Corresponding author Email: miorazman@utp.edu.my
}

\begin{abstract}
The manuscript should contain an abstract. The abstract should be self-contained and citation-free and should not exceed 200 words. The abstract should state the purpose, approach, results and conclusions of the work. The author should assume that the reader has some knowledge of the subject but has not read the paper. Thus, the abstract should be intelligible and complete in it-self (no numerical references); it should not cite figures, tables, or sections of the paper. The abstract should be written using third person instead of first person.

Intensive researches are being carried out on the main power generator for free piston linear generator(FPLG) by both the academic and industrial research group due to its potential as a high fuel efficiency and low emission engine. The linear generator, which is a coil and a translator positioned to move linearly back and forth relative to each other. The study investigates the heat transfer data of internal combustion engine with free piston linear motion profile and compared with the conventional reciprocating engine for one cycle motion only. Engine simulation software GT-Power is employed which utilize the 1-D thermodynamic modeling. All parameters for both free-piston engine are set-up to be the same except for the piston motion profile and the injection timing. Both conventional and free piston engine models are built, simulation settings are set up, and simulations are launched in GT-ISE. Once simulation is done, results are viewed in GT-POST, the data collected was analysed and compared to investigate the dictinct effect of piston motion to heat transfer profile and data. The overall trend shows that free piston engine have a lower heat transfer rate throughout majority of the cycle. This finding agrees that due to less time of piston near top dead centre area, heat transfer losses to the wall per cycle are reduced. The heat transfer profile of the free piston also shown distinct feature compared to conventional with rapid increase and decrease of heat transfer rate, followed by a secondary peak of gradual decline of the profile.
\end{abstract}

Keywords: Wall heat transfer; internal combustion engine; free piston; linear generator

\section{Introduction}

In the automotive industry, resurgence of interest revolves around free piston engines as an auxiliary power unit (APU) for a fully functional hybrid electric vehicles (HEVs). The expectations for the free piston engine includes extended driving range of vehicle, smaller batteries, which result in lighter faster vehicle, and shorter recharge time.

The word 'free-piston' describes its distinct behavior than the conventional reciprocating engine whereby it is without the constraint of the crank-slider movement. As the piston is free to make movement between its dead centers, the limiting factors are only the internal chamber pressure and load forces [1]. There are physical and behavioral differences between conventional and free piston engine. Major physical differences includes reduced number of parts for free piston engine which leads to reduction in frictional losses, lighter engine and absence of crankshaft [2]. These physical differences resulted in different piston velocity motion profile, whereby free piston engine moves linearly while conventional engine adapts a rotational motion. Free piston engine also has an improved piston acceleration around top dead centre.

In-cylinder heat transfer is a significant feature of internal combustion engines which affects engine performance and emissions. Hence, a single-cylinder of free piston engine is simulated to compare heat transfer characteristics of free-piston engine with a conventional engine. By modelling the piston motion and combustion profile, the heat transfer rate from the chamber wall can be obtained through 1-D quasi thermodynamic simulation; consequently predicting the engine performance, efficiency and fuel consumption. Hence, the predicting accurate heat transfer occurring in the combustion chamber of free piston linear generator is important for future development of free piston engine.

Free piston engine piston motion is considerably different from conventional engine, and its influences on the combustion process has yet to receive attention from researchers [4]. Hence, comparison between two distinct engines require assistance of software that is able to override the crank/slider sub-model to simulate the novel piston motion profiles of a free piston engines. Control needs to be determined and imposed to enable a fair comparison of engine performance between conventional engine and free piston engine.

Comparison of heat transfer results from internal combustion process both engines us carried out through a thermodynamic simulation out while taking into consideration the differences of free piston and conventional engine. The objectives of the study are to investigate the physical and behavioural difference between free piston engine and conventional engine using identified correlations of heat transfer and combustion models. 


\section{Piston Motion}

A number of authors have stated that piston motion profile is the most significant dissimilarity between conventional and free piston engines. According to Figure 1, the speed occurs in the middle of stroke between two extreme piston stop position, namely top dead centre (TDC) and bottom dead centre (BDC).

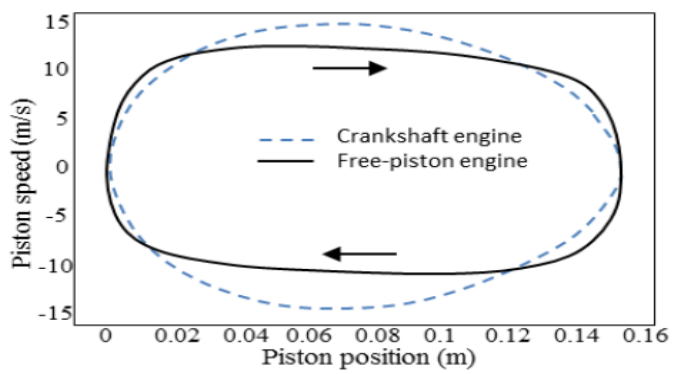

Fig 1. Piston speeds of conventional engine and free piston engine [1]

It has been shown that the piston velocity profiles are different between free piston and conventional engine. In conventional crankshaft engine, the maximum average piston speed is constrained by material safe limit and gas flow into and out of the cylinder [5]. Influence on piston motion within period of one cycle is hindered due to high inertia in the system.

Whereas in free piston engines, instantaneous force balance on the translator controls the piston motion, signifying the progress of combustion will affect speed of expansion. Significantly higher piston acceleration around top dead centre is reported in free piston piston motion profile [6]. Lowered thermal efficiency may occur due to high piston acceleration around TDC led to higher volume changes for combustion. Faster power stroke expansion after TDC potentially reduce temperature-dependent emissions formation and reduce heat transfer losses [7].

Piston motion is controlled by the crankshaft in conventional engines, ensuring a sufficient time for scavenging in one end and sufficient compression ratio for auto-ignition in the other. The lack of this mechanism gives the free piston engine the possible advantageous feature of variable compression ratio [8].

\section{Methodology}

\subsection{Modelling Software}

The software that was used for simulating the thermodynamic study of heat transfer losses in both combustion chamber is GT Power. The software is an engine simulation tool used for engine performance analysis. All information required to simulate a thermodynamic model was acquired from assistance of Centre for Automotive Research and Energy Management (CAREM) staff.

GT-ISE was used as the main interface in GT Power where engine models were built, simulation settings were set up, and simulations are launched. It is an environment where engine components were brought into a project map and connected together linking the entire model as a whole.

\subsection{Engine Specification}

The following sections focus on correlating two distinct engines to one another in order to obtain results of simulation that are comparable to one another. The subroutine uses the simulation results for a given conventional diesel engine configuration and runs a subsequent simulation for a free-piston engine with the same configuration and operational variables (bore, stroke, compression ratio, injected fuel mass, fuel, etc.), but with a piston motion equal to that of a free piston engine and injection timing to maximize fuel efficiency.

In order to model the cylinder geometry, the detailed values for the cylinder geometry are consistent with the engine specifications from [2]. Table 1 below listed the engine specifications that were used in this project.

Table 1. Engine Specification

\begin{tabular}{|c|c|c|}
\hline Engine & Conventional & Free piston \\
\hline & \multicolumn{2}{|c|}{0.150} \\
\hline Stroke (m) & \multicolumn{2}{|c|}{0.131} \\
\hline Bore (m) & \multicolumn{2}{|c|}{2000} \\
\hline Speed (rpm) & \multicolumn{2}{|c|}{$16: 1$} \\
\hline Compression ratio & \multicolumn{2}{|c|}{ Diesel } \\
\hline Fuel & \multicolumn{2}{|c|}{22 stroke } \\
\hline Injected fuel mass (mg) & -21 & -19 \\
\hline Operation & & \multicolumn{2}{|c|}{} \\
\hline Start of Injection $\left({ }^{\circ}\right)$ &
\end{tabular}

\subsection{Engine Simulation}

The following procedures were carried out for a one-dimensional simulation by means of single cylinder engine model. The aim is to simulate the combustion processes and record heat losses from combustion chamber wall of both conventional and free piston engine. The combustion model used in this study was "DI-Jet combustion" model of the GT-Power. In addition, the heat transfer to the walls of the cylinder was based on Woschni correlation.

\subsection{Conventional Reciprocating Engine Set-up}

The development of the two-stroke direct-injection (DI) single cylinder diesel engine, modelling in one-dimensional simulation was set up according to the steps given: (1) GT-Ise was launched. Templates were imported into the project. Templates needed for the project are listed in the following Table 2. (2) Templates with attributes of a conventional two-stroke diesel engine are defined. (3) Parts on the project map and link components together are arranged as shown in Figure 9. (4) Once the model was built, parameters with engine specifications are set up. Operations of conventional diesel engine are then simulated. (5) GT-Post was launched. Results obtained here were analysed. Parameters were altered to refine the results recorded.

Table 2. Templates imported from GT-Power

\begin{tabular}{|ll|}
\hline Flow Folder & Mech Folder \\
\hline EndEnvironment & EngineCrankTrain \\
\hline EngCylinder & \\
\hline Pipe & \\
\hline InjAF-RatioConn & \\
\hline OrificeConn - def & \\
\hline OrificeConn - bellmouth & \\
\hline ValveCamConn \\
\hline FPropGas - diesel-vap \\
\hline FPropGas - n2-vap \\
\hline FPropGas - o2-vap \\
\hline FPropLiqIncomp - diesel-combust \\
\hline FPropMixtureCombust - air \\
\hline
\end{tabular}

\subsection{Free Piston Engine Set-up}

Free piston engine was set up according to a study published by [9] for GT-Suites User Conference. For summary, the procedure performed for simulation of free piston engine are as follows: (1) From the free-piston motion profile shown in Figure 2, piston position at different time interval for free piston engine were extracted and recorded. (2) Piston position at different crank angle and time were determined. (3) "EngCylGeomUser" template was used. Free piston engine piston positioning from [2] were keyed in to "XYTable" template to simulate non-symmetric piston motion. 
(4) Injection timing was altered. Operations of free piston engine were simulated. (5) GT-Post was launched. Results obtained here were analysed. Parameters were altered to refine the results recorded.

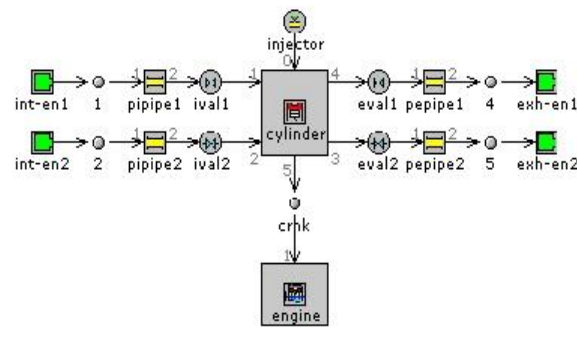

Fig. 2: GT-Power engine simulation set-up

\section{Results and Discussions}

This section discusses on the results obtained after completion of simulation and draw conclusion base on observable results. GT Power is widely used in engine research community for engine modelling, regardless of different configurations: spark-ignition, diesel, turbocharged, supercharged and etc. However, the version that is available in this study has yet to incorporate linear piston engine in the set-up. Hence, there is a need to validate the approach of this study which pre-determines piston position following the same acceleration and deceleration of a known piston motion profile from literature review.

Figure 3 was simulated using the engine specification for free piston engine using GT Power. The simulated pressure profile present similar features with the validated simulation result from [2]. Therefore, validating the free piston engine model being used in this study. Both graphs plummeted after reaching maximum pressure and decreases at a slower rate halfway through the linear piston movement. Both graphs also shown that difference of pressure during combustion and during reverse motion powered by the bounce chamber are small.

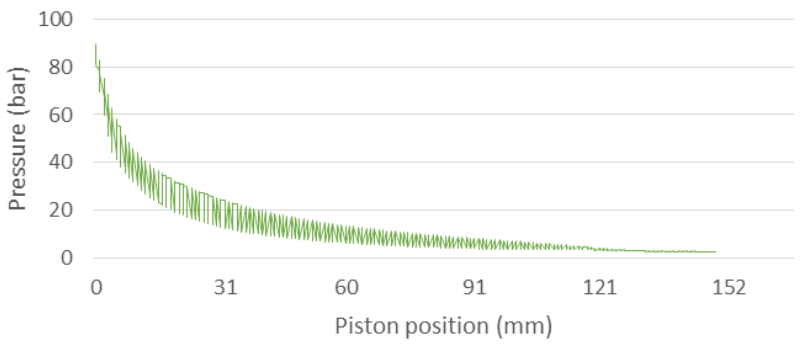

Fig. 3: Simulated combustion cylinder pressure for one cycle

Heat Release Rate (HRR) is the result of the combustion of a fuel with oxygen in air. Figure 4 and 5 shows the comparison of HRR versus crank angle for both conventional and free piston engines. Higher HRR shown in free piston engine allows the higher energy to be transferred into the pistons, resulting in higher thermal efficiency.

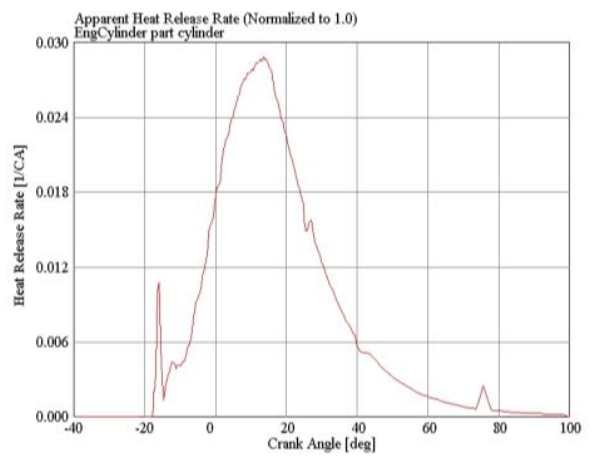

Fig. 4: Heat release rate vs crank angle (conventional)

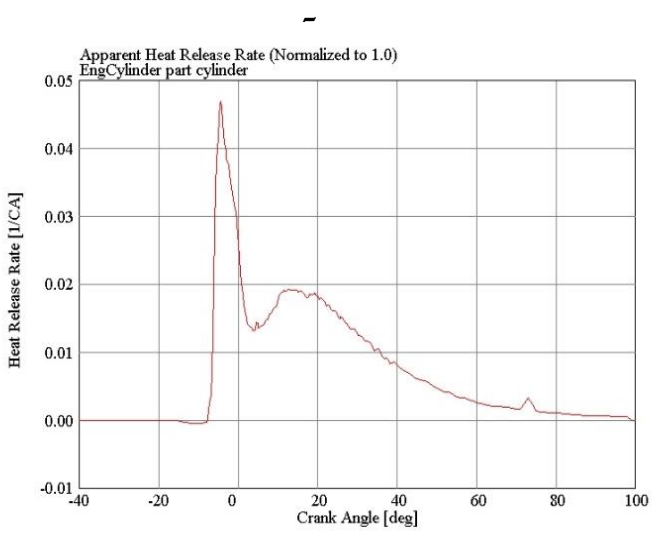

Fig. 5. Heat release rate vs crank angle (free piston)

Due to lower compression ratio during start of fuel injection in free piston engine, an increased ignition delay was observed from Figure 5. This phenomenon correlates well with physical attributes of free piston and the absence of crankshaft restriction. Hence, the peak pressure at top dead centre for free piston engine is recorded at a lower value.

From Figure 6 and 7, it can be observed that the shape of heat transfer profile is significantly different for conventional and free-piston engine. For conventional engine, the shape is seems rise and drop steadily with an almost same slope. While for free-piston, the heat transfer rate rises sharply and decline rapidly with and additional secondary peak after the decline. This adheres to the fact of distinct flow motion of the free-piston of higher acceleration near the TDC

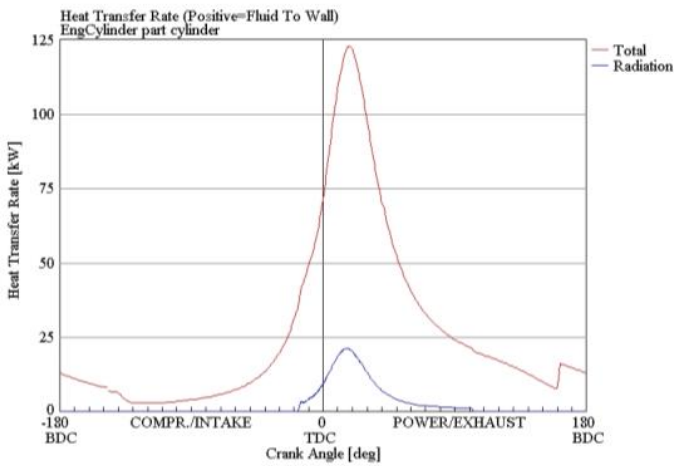

Fig. 6: Heat transfer rate vs crank angle (conventional)

When heat transfer losses increase, the work/cycle transferred to the piston will decrease, and the average combustion gas temperature and pressure will decrease. Figure 8 shows the overlapping of heat transfer losses through combustion chamber wall for free piston engine (FPE) and conventional engine. Between crank angle 
ranging from $0^{\circ}$ till $4.3^{\circ}$, FPE approaches peak heat transfer rate, $106.16 \mathrm{~kW}$ and FPE have a higher heat transfer rate than conventional engine. Conventional engine hits peak heat transfer rate of $113.47 \mathrm{~kW}$ at $19.5^{\circ}$. The overall trend shows that FPE have a lower heat transfer rate throughout majority of the cycle.

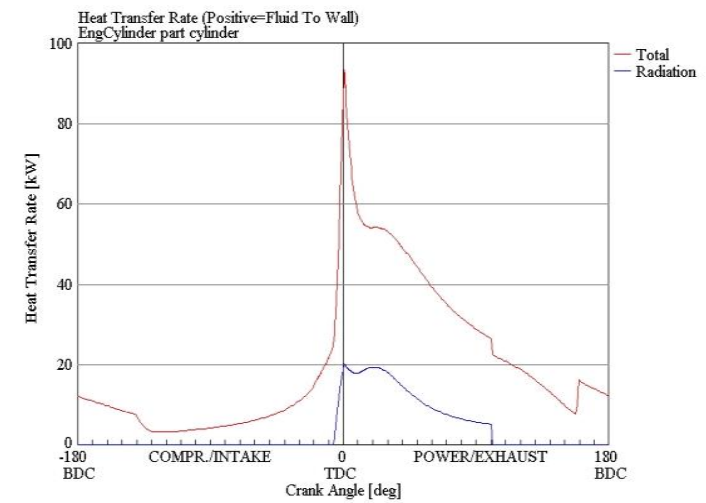

Fig. 7: Heat transfer rate vs crank angle (free piston)

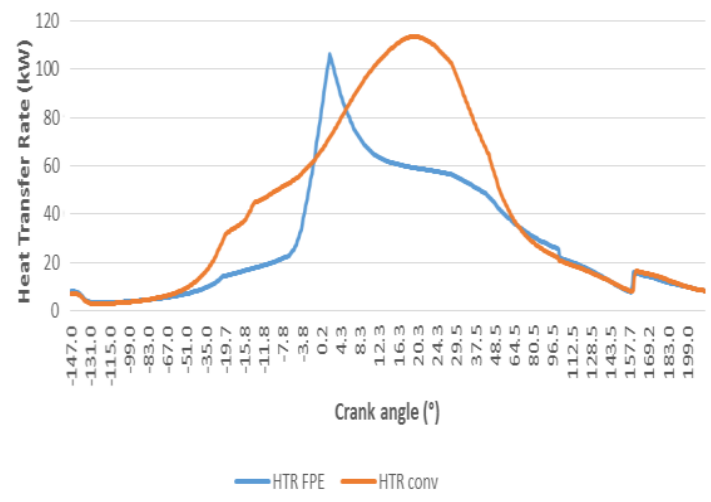

Fig. 8: Heat transfer rate comparison between conventional reciprocating engine and free-piston engine

This findings agree with Mikalsen \& Roskilly (2007), which postulates that due to less time of piston near top dead centre area, heat transfer losses to the wall per cycle are reduced. It can be noticed that the sharp increased and decrease from peak heat transfer rate points to the fact that rapid movement near top dead centre, which corresponds to the characteristics of linear engine piston motion profile.

\section{Conclusion}

A quasi-dimensional 1-D simulation model was used to investigate piston motion, the combustion process and heat transfer rate from combustion chamber and their effects on engine performance. The results for free piston engine were compared to a similar conventional engine in order to identify potential differences in engine performance. The heat transfer profile of the free piston shows distinct feature compared to conventional with rapid increase and decrease of heat transfer rate, followed by a secondary peak of gradual decline of the profile. The rapid motion of free piston profile reduces heat transfer losses near the top dead centre with the FPE recorded $106.16 \mathrm{~kW}$ compared to conventional reciprocating engine at $113.47 \mathrm{~kW}$.

\section{Acknowledgement}

The work was supported by the Center of Automotive Research and Electrical Mobility (CAREM) of Universiti Teknologi PETRONAS under Petronas Research Fund entitled "Develop- ment of a Concept-Demonstrator Free-Piston Linear Generator Powered by Flexi-Fuel".

\section{References}

[1] Mikalsen R. \& Roskilly A.P. "A Review of Free-piston Engine History and Applications", Applied Thermal Engineering, Vol.27, No.14-15, (2007), pp. 2339-2352, available online: https://www.sciencedirect.com/science/article/pii/S1359431107000 968, last visit.24.5.2018

[2] Mikalsen R. \& Roskilly A.P, Performance Simulation of a Spark Ignited Free-Piston Linear Generator, University of Newcastle, (2007).

[3] Feng H., Guo C., Yuan C., Guo Y., Zuo Z. \& Roskilly A.P. . "Research on combustion process of a free piston diesel linear generator". Appl. Energy Vol 161, pp. 395-403 https://www.sciencedirect.com/science/article/pii/S0306261915012 969, last visit 24.5.2018

[4] Hanipah M.R., Development of A Spark Ignition Free-Piston Engine Generator. Newcastle University (2015)

[5] Pulkrabek W., Engineering Fundamentals of the Internal Combustion Engine. Prentice-Hall, Inc. (1997)

'] Terry A. J. \& Michael T. L., Experimental Evaluation of the Free Piston Engine - Linear Alternator (FPLA), Sandia National Laboratories., (2015) SAND2015-2095569665

[7] Somhorst J.H.E. \& Achten P.A.J. "The Combustion Process in a DI Diesel Hydraulic Free Piston Engine”, SAE Paper 960032.

[8] Atkinson C.M., Petreanu S, Clark N.N., Atkinson R.J., McDaniel T.I., Nankumar S. "Numerical Simulation of a Two Stroke Linear Engine-alternator Combination", SAE Paper 1999-01-0921.

[9] Sten. I., 2000. "Simulation of a Two-Stroke Compression Ignition Hydraulic Free Piston Engine.”, GT-Suite Users Conference. Helsinki University of Technology (2000). 